\title{
Erratum to: Phenotypic and genetic characterization of varicella-zoster virus mutants resistant to acyclovir, brivudine and/or foscarnet
}

\author{
Karoline Bleymehl · Jindrich Cinatl • \\ Jonas Schmidt-Chanasit
}

Published online: 23 June 2012

(c) Springer-Verlag 2012

\section{Erratum to: Med Microbiol Immunol (2011) 200:193-202 \\ DOI 10.1007/s00430-011-0191-4}

The authors would like to correct the errors in the original publication of the article. The errors include details under the sub-headings "Sequence evolution of selected VZV genes in resistant Mutants", Discussion, and in Figs. 3 and 4 and Table 3. The corrected sentences, figures and table are given below for your reading.

As the amino acid substitutions Asn479Ile and Arg601Met were observed in the viral DNA polymerase (vDNA pol) and not in the viral thymidine kinase (vTK), the following sentences were modified accordingly.

The corrected paragraph under the sub-heading "Sequence evolution of selected VZV genes in resistant mutants" should read:

The online version of the original article can be found under doi:10.1007/s00430-011-0191-4.

\footnotetext{
K. Bleymehl · J. Cinatl

Institute of Medical Virology, Hospital of the Johann Wolfgang Goethe University, 60596 Frankfurt am Main, Germany

J. Schmidt-Chanasit

Department of Virology, Bernhard-Nocht-Institute for Tropical Medicine, Bernhard-Nocht-Strasse 74, 20359 Hamburg, Germany

J. Schmidt-Chanasit $(\bowtie)$

Department of Virology, Clinical Virology Laboratory,

Bernhard-Nocht-Strasse 74, 20359 Hamburg, Germany

e-mail: jonassi@gmx.de
}

After adaptation, a selection of genes (Table 1) of all resistant isolates and corresponding parental virus controls was amplified and sequenced. In 7 of 9 of the resistant strains, nucleotide exchanges were found in at least one analyzed ORF (Table 3). Exclusively, only the MR-PFA mutant showed nucleotide exchanges although the IC50 values of all resistant MR isolates increased beyond the tenfold of cutoff values. Nucleotide exchanges were mainly found in the viral thymidine kinase gene (vTK, ORF 36, Fig. 4) as well as in the viral DNA polymerase gene (vDNApol, ORF 28, Fig. 3). Sequence analysis of our resistant isolates revealed several mutations in the vTK gene resulting in aa substitutions. One aa exchange was found in ACV-resistant isolate PP, namely at positions 256 (Thr $\rightarrow$ Met), whereas BVdU-resistant isolates PP-BVdU and 06-BVdU contained exchanges at positions 62 (Ile $\rightarrow$ Phe) and 85 (Leu $\rightarrow$ Pro). In addition, strain 06-BVdU contained a premature stop codon at codon position 296 (Table 3). Interestingly, MR-PFA displayed an aa exchange at codon position 92 (Leu $\rightarrow$ Met) within the vTK gene although PFA does not depend on vTK phosphorylation and pharmacologically affects the vDNA pol. Mutations within the vDNA pol (ORF 28) of our isolates led to aa exchanges at positions 684 (Aln $\rightarrow$ Val) and 804 (Ile $\rightarrow$ Thr) in isolate PP-PFA, in isolate 06-PFA at positions 662 (Lys $\rightarrow$ Glu) and 773(Ala $\rightarrow$ Val), and in isolate MR-PFA at position $680(\mathrm{Val} \rightarrow$ Ala) (Table 3). 06-ACV presented exchanges at positions 479 (Asn $\rightarrow$ Ile) and 601 (Arg $\rightarrow$ Met) as well as PP-ACV, which showed one exchange at position 1180 (Met $\rightarrow$ Thr). Additionally, isolate PP-BVdU also showed nucleotide exchanges in the important viral transactivator IE 62 gene (ORF 62) and in the viral glycoprotein gI gene (ORF 67). The sequences of the PP-BVdU IE 62 and gI genes were compared to other sequences listed in NCBI by using the BLAST algorithm 
Table 3 Non-silent mutations found in resistant isolates and corresponding amino acid substitutions

Fig. 3 Amino acid substitutions found within the vDNA pol encoded by ORF28. Black boxes indicate highly conserved regions. Mutations found in our resistant isolates are indicated in red

\begin{tabular}{|c|c|c|c|c|}
\hline $\begin{array}{l}\text { Resistant isolates } \\
\mathrm{IC}_{50}\end{array}$ & ORF & Protein & $\begin{array}{l}\text { Nucleotide position } \\
\text { and substitution }\end{array}$ & $\begin{array}{l}\text { Amino acid position } \\
\text { and substitution }\end{array}$ \\
\hline \multicolumn{5}{|l|}{$\mathrm{ACV}$} \\
\hline \multirow[t]{2}{*}{$\mathrm{PP} / 753.5 \mu \mathrm{M}$} & 28 & vDNA pol & T $3539 \mathrm{C}$ & Met $1180 \mathrm{Thr}$ \\
\hline & 36 & vTK & C $767 \mathrm{~T}$ & Thr $256 \mathrm{Met}$ \\
\hline \multirow[t]{2}{*}{$06 / 4289 \mu \mathrm{M}$} & 28 & vDNA pol & A $1436 \mathrm{~T}$ & Asn 479 Ile \\
\hline & 28 & vDNApol & G $1802 \mathrm{~T}$ & Arg $601 \mathrm{Met}$ \\
\hline $\mathrm{MR} / 1610.5 \mu \mathrm{M}$ & & & None & None \\
\hline \multicolumn{5}{|l|}{$\mathrm{BVdU}$} \\
\hline \multirow[t]{3}{*}{$\mathrm{PP} / 3180 \mu \mathrm{M}$} & 36 & vTK & A $184 \mathrm{~T}$ & Ile 62 Phe \\
\hline & 62 & IE 62 & A $3071 \mathrm{G}$ & Gln 1024 Arg \\
\hline & 67 & $\mathrm{gI}$ & G $101 \mathrm{~A}$ & Ser 34 Asn \\
\hline \multirow[t]{2}{*}{$06 / 963 \mu \mathrm{M}$} & 36 & vTK & T $254 \mathrm{C}$ & Leu 85 Pro \\
\hline & 36 & vTK & T $887 \mathrm{G}$ & Leu 296 Stop \\
\hline $\mathrm{MR} / 719 \mu \mathrm{M}$ & & & None & None \\
\hline \multicolumn{5}{|c|}{ PFA } \\
\hline \multirow[t]{2}{*}{$\mathrm{PP} / 811 \mu \mathrm{M}$} & 28 & vDNA pol & C $2051 \mathrm{~T}$ & Ala 684 Val \\
\hline & 28 & vDNA pol & T $2411 \mathrm{C}$ & Ile $804 \mathrm{Thr}$ \\
\hline \multirow[t]{2}{*}{$06 / 1321 \mu \mathrm{M}$} & 28 & vDNA pol & A $1984 \mathrm{G}$ & Lys 662 Glu \\
\hline & 28 & vDNA pol & C $2318 \mathrm{~T}$ & Ala 773 Val \\
\hline \multirow[t]{2}{*}{$\mathrm{MR} / 1326 \mu \mathrm{M}$} & 28 & vDNA pol & T $2039 \mathrm{C}$ & Val 680 Ala \\
\hline & 36 & vTK & C $274 \mathrm{~A}$ & Leu $92 \mathrm{Met}$ \\
\hline
\end{tabular}

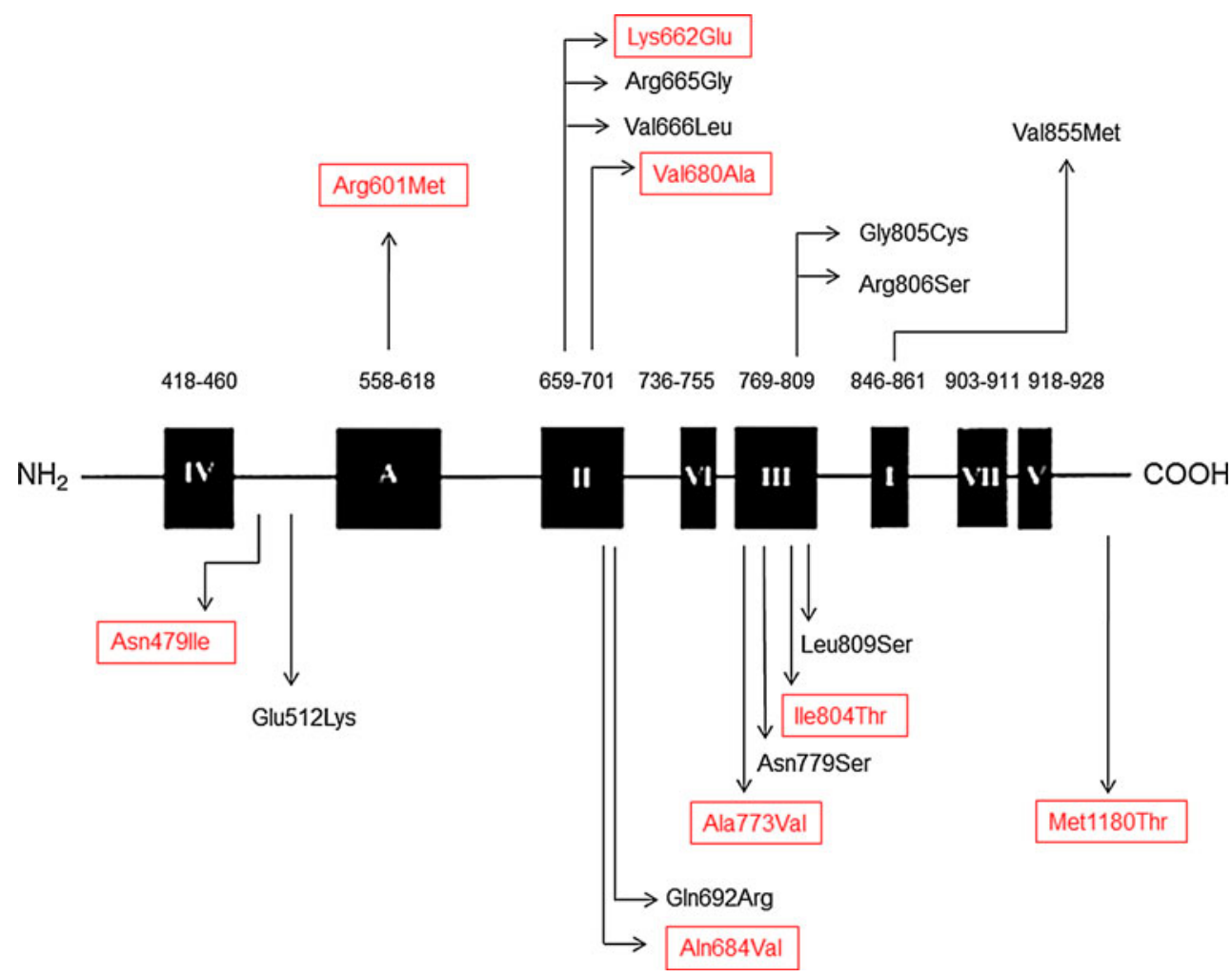

[12-20]. None of our detected base exchanges (A $3071 \mathrm{G}$, G 101 A, Table 3) were issued in this database.

The corrected sentences under Discussion are given below. The second sentence should read as:
Even though only one aa substitution found at position 62 (Ile $\rightarrow$ Phe) in isolate PP-BVdU is located within the active domain of the ATP-binding site of the vTK, the post-adaptational IC50 of the resistant isolates 06-BVdU, 


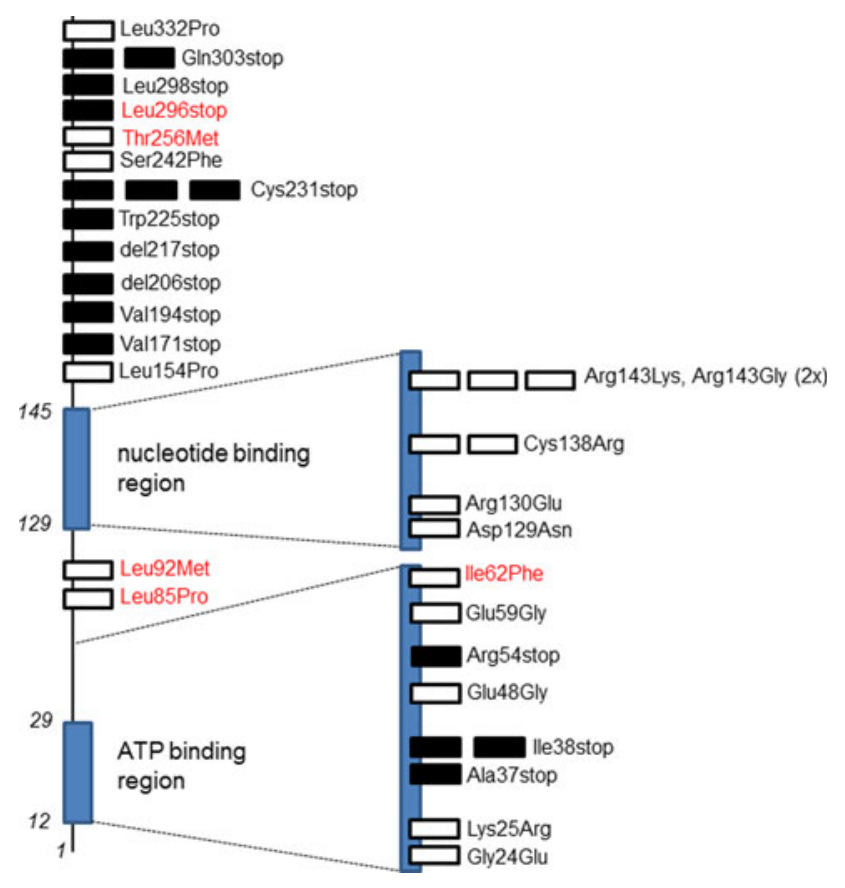

Fig. 4 Amino acid substitutions within the viral thymidine kinase (vTK). Filled boxes indicate stop codons, and empty boxes indicate aa substitutions. Blue boxes represent functional domains of the protein. Mutations found in our resistant isolates are indicated in red
PP-ACV/BVdU and MR-PFA exhibited a distinct rise beyond the tenfold proving resistance toward ACV.

In second paragraph, the fourth sentence should read as:

These findings suggest a complete loss of the functional activity of the vTK, although all other aa substitutions are located peripheral to the active ATP-binding site.

In fifth paragraph, the fourth sentence should read as:

All of our clinical isolates resistant to PFA presented aa substitutions, five in total, whereas three nt substitutions within the vDNA pol gene resulting in aa exchanges were found in ACV-resistant isolates PP-ACV and 06-ACV. Interestingly, 5 of 8 of these substitutions appeared within regions II and III.

The authors would like to apologize for any inconvenience this may have caused to the readers of the journal. 